\title{
Pengaruh Stres Kerja Terhadap Kinerja Karyawan The Influence of Job Stress on Employees Job Performance
}

\author{
Nadia Antonita Christy ${ }^{1 *}$ dan Sholihati Amalia ${ }^{2}$ \\ ${ }^{1}$ Jurusan Administrasi Niaga, Politeknik Negeri Bandung, Indonesia \\ 2 Jurusan Administrasi Niaga, Politeknik Negeri Bandung, Indonesia
}

\begin{abstract}
:
Every employee must have experienced job stress. Work stress can give positive effect but if excessive it will cause negative impact especially is on employee performance. Therefore work stress must be prevented and handled. Excessive job stress is also experienced by employees of production department at PT Catur Kartika Jaya which is engaged in making mosquito nets. Therefore this research was made to find out how the job stress that faced by employees of the production of PT Catur Kartika Jaya and its influence on the performance of these employees. The results obtained through this study is that there is a strong and significant negative influence on work stress on the performance of production employee in PT Catur Kartika Jaya. Therefore, the authors suggest the company to do socialization about work stress management and various activities outside the work that can rest and refresh the soul and body.
\end{abstract}

Keywords: job stress, employees performance, employees productivity

\begin{abstract}
Abstrak:
Setiap karyawan pasti pernah mengalami stres kerja. Stress kerja bisa memberi efek positif namun jika berlebihan maka akan menimbulkan dampak negatif terutama pada kinerja karyawan. Oleh karena itu stres kerja harus dicegah dan ditangani. Tekanan kerja yang berlebihan juga dialami oleh karyawan departemen produksi di PT Catur Kartika Jaya yang bergerak dalam pembuatan kelambu. Oleh karena itu penelitian ini dilakukan untuk mengetahui bagaimana tekanan kerja yang dihadapi karyawan produksi PT Catur Kartika Jaya dan pengaruhnya terhadap kinerja karyawan tersebut. Hasil yang diperoleh melalui penelitian ini adalah ada pengaruh negatif yang signifikan dan signifikan terhadap stres kerja terhadap kinerja pegawai produksi di PT Catur Kartika Jaya. Oleh karena itu, penulis menyarankan perusahaan untuk melakukan sosialisasi tentang manajemen stres kerja dan berbagai kegiatan di luar pekerjaan yang dapat beristirahat dan menyegarkan jiwa dan raga.
\end{abstract}

Kata Kunci: stres kerja, kinerja karyawan, produktivitas karyawan

\section{PENDAHULUAN}

Karyawan merupakan suatu aset penting bagi perusahaan, karena produktivitas perusahaan tergantung pada mereka. Oleh karena itu perusahaan harus

* Email Korespondensi:

Nadia Antonita Christy

antonichristy@gmail.com

Jurnal Riset Bisnis \& Investasi

Vol. 3, No. 2, Agustus 2017

ISSN 2460-8211 mengelola karyawan dengan sangat baik agar karyawan merasa nyaman. Faktor kenyamanan bagi karyawan merupakan sesuatu yang harus diperhatikan oleh perusahaan agar karyawan betah bekerja di perusahaan tersebut sehingga karyawan akan menjadi loyal, dengan demikian kinerja mereka akan semakin baik. Namun 
sebaliknya, jika karyawan merasa tidak nyaman, maka akan menimbulkan stres kerja yang dapat mengakibatkan rasa tertekan. Stres kerja ini akan menimbulkan kinerja karyawan tidak baik yang nantinya akan merugikan perusahaan seperti dikatakan Kotteswari, et al., (2014) bahwa terdapat pengaruh negatif antara stres kerja dengan kinerja karyawan. Greenbergdalam Mauladi dan Dihan (2015: 51) mengatakan bahwa "stres kerja adalah kondisi yang muncul dari interaksi antara manusia dan pekerjaan serta dikarakterisasikan oleh perubahan manusia yang memaksa mereka untuk menyimpang dari fungsi normal mereka."

Stres kerja juga dialami oleh karyawan pada bagian produksi PT. Catur Kartika Jaya Bandung. PT. Catur Kartika Jaya Bandung adalah sebuah perusahaan yang bergerak di bidang produksi kelambu. Dalam proses produksi kelambu, sering kali produk mengalami cacat produksi sehingga produk tersebut tidak dapat dijual dan merugikan perusahaan. Selain itu beberapa kali perusahaan tersebut tidak dapat mencapai target produksi. Berdasarkan data yang didapat dari perusahaan, dapat diketahui bahwa target produksi PT. Catur Kartika Jaya pada bulan Februari 2016Januari 2017 dalam 1 tahun adalah 40.071 lembar kelambu, sementara total kelambu yang gagal produksi adalah 1.682 lembar dan hasil produksi yang lulus standar untuk dijual adalah 39.445 lembar kelambu. Hal ini berarti rata-rata setiap bulannya $4,16 \%$ kelambu mengalami cacat produksi, padahal batas toleransi yang diterapkan perusahaan adalah 3\%.

Menurut wawancara pra penelitian yang dilakukan pada 15 dari 115 karyawan bagian produksi PT Catur Kartika Jaya, diketahui bahwa salah satu penyebab tidak tercapainya target hasil produksi yang lulus quality control serta banyak sekali mengalami cacat produksi adalah dikarenakan keteledoran para karyawan bagian produksi dalam bekerja. Perasaan tertekan oleh pekerjaan yang berat, terdesak oleh waktu, lelah, jenuh, dan bekerja lebih dari kemampuan mengakibatkan para karyawan mengalami stres sehingga para karyawan banyak melakukan kesalahan. Dampak terbesar dari stres yang para karyawan bagian produksi alami yaitu pada kinerja para karyawan bagian produksi yang menjadi kurang baik.

Selanjutnya berdasarkan pengamatan penulis, karyawan bagian produksi PT. Catur Kartika Jaya juga mengalami beberapa gejala perilaku orang yang mengalami stres kerja seperti produktivitas karyawan yang kurang baik yang terbukti dengan seringnya perusahaan tidak sampai pada target produksi, ketidakdisiplinan pada kehadiran dalam bekerja, banyaknya karyawan yang merokok pada jam istirahat dan juga ada beberapa karyawan yang kurang ramah saat penulis menanyakan beberapa pertanyaan. Selain itu berdasarkan wawancara penulis dengan 15 orang karyawan bagian produksi PT Catur Kartika Jaya, para karyawan juga sering mengalami kelelahan fisik, sering mengalami sakit kepala ketika terlalu tertekan karena banyaknya produk yang harus diselesaikan serta sering terlambat makan siang. Berdasarkan latar belakang dan data yang telah di uraikan sebelumnya, dapat diindakasikan bahwa stres kerja berpengaruh negatif terhadap kinerja karyawan. Hal tersebut diatas mendorong penulis untuk melakukan penelitian tentang pengaruh stres yang dialami oleh para karyawan dan dampaknya terhadap kinerja karyawan pada bagian produksi.

\section{TINJAUAN PUSTAKA}

\section{Stres Kerja}

Rivai dan Mulyadi (2013: 308) mengatakan bahwa "stres kerja adalah dikarenakan adanya ketidakseimbangan antara karakteristik kepribadian karyawan dengan karakteristik aspek-aspek 
pekerjaannya dan dapat terjadi pada semua kondisi pekerjaan.“. Zafar, et.al (2015) mengatakan bahwa stres terbagi dua, yaitu Eustress (stres yang dapat merangsang kinerja seseorang dan secara positif dapat mendorong karyawan untuk menghasilkan sesuatu yang lebih baik) dan distress (stres yang menghasilkan efek negatif pada kesehatan dan kinerja karyawan).

Stres kerja yang dialami seseorang menurut Davis dan Newstrom dalam Rivai dan Mulyadi (2013) disebabkan karena tugas yang terlalu banyak sehingga dapat menimbulkan stres bila kuantitas tugas tidak seimbang dengan kemampuan yang dimiliki karyawan, supervisor yang tidak terampil, batas waktu yang terlalu singkat dalam menyelesaikan pekerjaan, tidak dipercaya dalam melakukan suatu tanggung jawab, ambiguitas peran, berbedanya nilai individu dengan perusahaan, frustrasi, perubahan dalam jenis pekerjaan yang dilakukan dan adanya konflik dalam peran yang dijalankan. Maka dari itu stres kerja dapat dikurangi dengan menggunakan manajemen waktu yang ketat, rileks, banyak beristirahat, santai, belajar untuk mendengarkan, memperbaiki lingkungan, tidak memusingkan hal kecil, banyak tidur, mendapatkan bimbingan, berteman dengan orang-orang optimis, kenali stressor, kendalikan apa yang dipikirkan. Menurut Hidayanti dan Trisnawati (2016), dimensi dan indikator stres kerja adalah:

1. Ambiguitas Peran

Indikator: Pekerjaan yang banyak

2. Pengembangan Karir

Indikator: Tidak adanya pengembangan karir

3. Hubungan Kerja

Indikator: pikiran yang tidak sejalan dengan rekan kerja, dibuli teman, bekerja diluar jam kantor

\section{Kinerja Karyawan}

Menurut Darodjat (2015: 105) "kinerja mempunyai pengertian akan adanya suatu tindakan atau kegiatan yang ditampilkan oleh seseorang dalam melaksanakan aktivitas tertentu yang menjadi tugasnya."

Maka dari itu, untuk mengetahui bagaimana kinerja karyawan, perusahaan perlu melakukan evaluasi atau penilaian kinerja karyawan. Menurut Widodo (2015:130) "penilaian kinerja adalah suatu evaluasi terhadap tingkat kinerja seseorang dibandingkan dengan standar kinerja yang sudah ditentukan, guna bahan pertimbangan dalam menentukan promosi, kompensasi, perlunya pelatihan atau pengembangan, maupun untuk pemberhentian seseorang." Menurut Bangun (2012) dimensi dan indikator kinerja yaitu:

1. Kuantitas pekerjaan

Melakukan pekerjaan sesuai target

2. Kualitas pekerjaan

- Melakukan pekerjaan sesuai oper ation manual

- Melakukan pekerjaan sesuai ins pection manual

3. Ketepatan waktu

- Menyelesaikan pekerjaan sesuai dedlline

- Kehadiran

- Datang tepat waktu

- Bekerja sesuai jam kerja

4. Kemampuan kerja

- Memberi saran pada atasan untuk meningkatkan produktivitas organisasi

- Menghargai rekan kerja satu sama lain

- Bekerja sama dengan rekan kerja secara baik

\section{Hubungan Stres Kerja dengan Kinerja Karyawan}

Menurut Wu, 2011; Yozgat et al., 2013; Hidayati et al., 2013 dalam Mauladi dan Dihan (2015) stres kerja mempunyai pengaruh yang negatif terhadap kinerja 
karyawan. Stres kerja sering dipandang sebagai efek disfungsional yang dapat menurunkan kinerja baik dari segi kualitas maupun kuantitas pekerjaan itu sendiri. Dikatakan bahwa karyawan dengan tingkat stres yang rendah akan memiliki kinerja yang tinggi.

Sementara menurut Olusegun, dkk (2014) dalam penelitian indikator stres seperti beban kerja berlebihan, ingin mengembangkan karir, konflik kerja/keluarga, kelelahan, cemas, tidak bahagia, lemah, sakit kepala dapat mempengaruhi kinerja karyawan sebesar $56,9 \%$.

\section{METODE PENELITIAN}

Variabel dalam penelitian ini adalah stres kerja (variabel X) dan kinerja karyawan (variabel Y). Untuk dapat mengetahui stres kerja dan kinerja karyawan bagian produksi PT. Catur Kartika Jaya, maka objek sekaligus populasi pada penelitian ini adalah karyawan bagian produksi PT. Catur Kartika Jaya. Sementara sampel yang digunakan dalam penelitian ini menggunakan metode non probability sampling dengan menggunakan teknik sampling jenuh yang berarti semua anggota populasi dijadikan sampel.

Metode penelitian pada penelitian ini menggunakan pendekatan kuantitatif. Sementara sumber data yang didapat untuk penelitian ini adalah sumber data primer yang diperoleh dari wawancara, dan penyebaran kuesioner serta sumber data sekunder yang diperoleh dari media seperti buku, litearatur dan dokumen perusahaan.

\section{HASIL DAN PEMBAHASAN Identitas Responden}

Berdasarkan hasil olah data SPSS, berikut ini adalah identitas responden berdasarkan jenis kelamin, usia, periode bekerja dan pendidikan terakhir.
Tabel 1. Jenis Kelamin

\begin{tabular}{|c|c|c|c|}
\hline No. & Jenis Kelamin & Jumlah & $\%$ \\
\hline 1 & Perempuan & 67 & 58,3 \\
\hline 2 & Laki-laki & 48 & 41,7 \\
\hline & Jumlah & 115 & 100 \\
\hline
\end{tabular}

Sumber: Olah Data Penulis, 2017

Tabel 2. Usia

\begin{tabular}{|c|c|c|c|}
\hline No. & Usia & Jumlah & $\%$ \\
\hline 1. & 18-28 tahun & 47 & 40,9 \\
\hline 2. & 29-39 tahun & 55 & 47,8 \\
\hline 3. & $40-50$ tahun & 12 & 10,4 \\
\hline 4. & 51-60 tahun & 1 & 0,9 \\
\hline \multicolumn{2}{|c|}{ Jumlah } & 115 & 100 \\
\hline
\end{tabular}

Sumber: Olah Data Penulis, 2017

Tabel 3. Periode Bekerja

\begin{tabular}{|l|l|l|l|}
\hline No. & Usia & Jumlah & \% \\
\hline 1. & $1-5$ tahun & 25 & 21,7 \\
\hline 2. & $6-10$ tahun & 61 & 53,1 \\
\hline 3. & $11-20$ tahun & 28 & 24,3 \\
\hline 4. & $>20$ tahun & 1 & 0,9 \\
\hline Jumlah & 115 & 100 \\
\hline
\end{tabular}

Sumber: Olah Data Penulis, 2017

Tabel 4. Pendidikan Terakhir

\begin{tabular}{|l|l|l|l|}
\hline No. & Usia & Jumlah & $\%$ \\
\hline 1. & Dibawah SMA & 0 & 0 \\
\hline 2. & SMA/sederajat & 108 & 93,9 \\
\hline 3. & D-III & 4 & 3,5 \\
\hline 4. & D-IV & 3 & 2,6 \\
\hline \multicolumn{2}{|c|}{ Jumlah } & 115 & 100 \\
\hline
\end{tabular}

Sumber: Olah Data Penulis, 2017

\section{Analisis Deskriptif Stres Kerja}

Berdasarkan hasil olah data pada tabel 5, tingkat stres kerja yang dirasakan oleh karyawan bagian produksi di PT Catur Kartika Jaya berada pada kategori yang tinggi. Untuk dimensi pengembangan karir dan hubungan kerja, walaupun berada dalam kategori tinggi namun bersifat negatif. Hal ini dapat diketahui dari rata-rata jawaban 115 responden yaitu sebear 4,0608 yang berada pada interval 3,40-4,19. Menurut pengamatan penulis hal ini terjadi karena $58,3 \%$ yang artinya 
karyawan bagian produksi PT Catur Kartika Jaya didominasi oleh perempuan. dr. Judith Mohring dalam harian kompas.com (2017) mengatakan bahwa tingkat stres yang tinggi bisa terjadi kepada siapa saja, tetapi terutama di kalangan wanita. Menurut Mohring hal tersebut bisa disebabkan karena adanya seksisme di tempat kerja, kurangnya dukungan, dan kesulitan menyeimbangkan karier dan keluarga.

Tabel 5. Stres Kerja

\begin{tabular}{|l|l|l|l|}
\hline No. & Dimensi & Mean & Ket. \\
\hline 1. & $\begin{array}{l}\text { Ambiguitas } \\
\text { Peran }\end{array}$ & 4,67 & $\begin{array}{l}\text { Sangat } \\
\text { tinggi }\end{array}$ \\
\hline 2. & $\begin{array}{l}\text { Pengembangan } \\
\text { Karir }\end{array}$ & 4,67 & $\begin{array}{l}\text { Sangat } \\
\text { tinggi }\end{array}$ \\
\hline 3 & $\begin{array}{l}\text { Hubungan } \\
\text { kerja }\end{array}$ & 3,09 & Sedang \\
\hline $\begin{array}{l}\text { Nilai Rata-Rata Stres } \\
\text { Kerja }\end{array}$ & 4,0608 & Tinggi \\
\hline
\end{tabular}

Sumber: Olah Data SPSS, 2017

Selain itu menurut survei yang dilakukan Onepoll dalam harian suara.com (2016) umumnya orang akan mengalami puncak stres pada usia 36 tahun. Hal ini sejalan dengan hasil penelitian ini dimana $47,8 \%$ atau mayoritas karyawan bagian produksi di PT Catur Kartika Jaya ada pada rentang usia 29-39 tahun, maka dapat diartikan bahwa puncak stres memang sedang dialami oleh karyawan pada golongan usia ini. Lalu dapat dilihat juga dalam penelitian ini bahwa $53,1 \%$ atau mayoritas responden telah bekerja selama 6-10 tahun yang artinya mereka telah cukup lama bekerja dan menghadapi beban kerja yang berat sehingga mereka merasakan stres kerja.

Berdasarkan jawaban para responden dapat diketahui bahwa para responden benar-benar mengalami stres kerja dan stres kerja yang mereka rasakan berada pada kategori tinggi karena memiliki nilai-rata 4,0608 terutama pada dimensi ambiguitas peran dan pengembangan karir yang sama-sama memiliki nilai rata-rata 4,67. Hal ini mengartikan bahwa para karyawan memang mengalami ambiguitas peran serta tidak merasakan pengembangan karir selama bekerja di bagian produksi PT Catur Kartika Jaya. Ambiguitas peran yang dialami oleh para karyawan yaitu karena para karyawan bekerja dengan bidang kerja yang bermacam-macam. Dari semua bidang pekerjaan yang ada, setiap karyawan diwajibkan untuk bertanggung jawab untuk membantu mencapai target sesuai visi dan misi perusahaan dan terkadang mereka harus mengerjakan pekerjaan lain yang bukan tanggung jawab mereka. Oleh karena itu para karyawan dituntut untuk dapat bekerja lebih maksimal dan mampu menyelesaikan pekerjaan dengan batas waktu yang telah ditentukan perusahaan kepada mereka. Sementara menurut hasil wawancara penulis dengan manajer produksi PT Catur Kartika Jaya, alasan tidak adanya pengembangan karir adalah karena perusahaan ini sangat jarang membuka lowongan kecuali untuk buruh karena dari semua karyawan yang bekerja di PT Catur Kartika Jaya, hanya para buruh yang lumayan sering mengalami turnover sementara pada bagian lain jarang ada yang resign dari pekerjaan. Jadi jarang ada kesempatan untuk kenaikan jabatan. Selain itu alasan lain mayoritas karyawan tidak pernah mengalami kenaikan jabatan adalah karena pendidikan terakhir 93,9\% karyawan bagian produksi hanya SMA, lalu periode bekerja terlalu sebentar dan pengalaman bekerja yang kurang banyak juga menjadi alasan kurang berkembangnya karir para karyawan bagian produksi PT Catur Kartika Jaya.

\section{Analisis Deskriptif Kinerja Karyawan}

Berdasarkan hasil olah data pada tabel 6, dapat diketahui bahwa kinerja karyawan bagian produksi di PT Catur 
Kartika Jaya berada pada kategori yang cukup. Hal ini dapat diketahui dari ratarata jawaban 115 responden yaitu sebesar 2,6109 yang berada pada interval cukup. Tentu saja bagi sebuah perusahaan kategori cukup masih belum dapat dikatakan baik karena setiap perusahaan pasti menginginkan para karyawannya memiliki kinerja yang baik bahkan sangat baik.

Tabel 6. Kinerja Karyawan

\begin{tabular}{|l|l|l|l|}
\hline No. & Dimensi & Mean & Ket \\
\hline 1 & Kuantitas & 2,58 & Buruk \\
\hline 2 & Kualitas & 2,71 & Cukup \\
\hline 3 & Ketepatan & 2,10 & Buruk \\
\hline 4 & Kehadiran & 2,45 & Buruk \\
\hline 5 & Kerja Sama & 2,58 & Cukup \\
\hline $\begin{array}{l}\text { Nilai Rata - Rata } \\
\text { Kinerja Karyawan }\end{array}$ & 2,6109 & Cukup \\
\hline
\end{tabular}

Sumber: Olah Data SPSS, 2017

Dari kelima dimensi yang ada pada variabel kinerja karyawan, dimensi kemampuan kerja sama memiliki nilai ratarata paling tinggi yaitu 2,85 yang masuk dalam kategori cukup sementara dimensi ketepatan waktu memiliki nilai rata-rata paling rendah yaitu 2,10 yang masuk dalam kategori buruk. Dari kelima dimensi ini dapat diketahui bahwa kinerja karyawan bagian produksi PT Catur Kartika Jaya termasuk dalam kategori cukup.

Dari kelima dimensi dapat diketahui bahwa kinerja karyawan yang terhitung paling baik adalah kualitas pekerjaan mereka yang bernilai 2,71. Hal ini dikarenakan hasil pekerjaan para karyawan memang harus lulus uji Quality Control, hanya saja karena waktu yang terlalu mendesak banyak kualitas pekerjaan yang menjadi buruk pula karena dikejar waktu sehingga pekerjaan mereka harus diperbaiki sehingga dimensi kualitas pekerjaan ini hanya bernilai cukup. Sementara nilai kinerja yang rendah didapatkan dari ketepatan waktu para karyawan yang bernilai 2,10. Hal ini dikarenakan pekerjaan para karyawan melebihi batas kemampuan para karyawan sehingga menyebabkan waktu untuk menyelesaikan pekerjaan jadi terlambat.

\section{Analisis Pengaruh Stres Kerja Terhadap Kinerja Karyawan}

Melalui hasil analisis korelasi yang telah dilakukan terbukti bila korelasi stres kerja dan kinerja karyawan bersifat negatif karena memiliki nilai korelasi adalah 0,642 . Jika mengacu pada interpretasi nilai hasil analisis korelasi maka 0,642 masuk pada kategori kuat. Sehingga dapat dikatakan bahwa stres kerja dan kinerja karyawan memiliki hubungan negatif yang kuat dan hasil tersebut sangat signifikan karena nilai signifikansinya adalah 0,000 yang artinya kurang dari 0,005 .

Tabel 7. Hasil Analisis Korelasi

\begin{tabular}{|l|l|l|l|}
\hline & & $\begin{array}{c}\text { Stres } \\
\text { Kerja }\end{array}$ & $\begin{array}{l}\text { Kinerja } \\
\text { Karyaw } \\
\text { an }\end{array}$ \\
\hline $\begin{array}{l}\text { Stres } \\
\text { Kerja }\end{array}$ & $\begin{array}{l}\text { Pearson } \\
\text { Correlation } \\
\text { Sig. (2-tailed) } \\
\text { N }\end{array}$ & 1 & $-.642^{* *}$ \\
\hline Kinerja & $\begin{array}{l}\text { Pearson } \\
\text { Correlation }\end{array}$ & 115 & 115 \\
Karyawan & $\begin{array}{l}.000 \\
\text { Sig. (2-tailed) } \\
\text { N }\end{array}$ & .000 & 1 \\
\hline
\end{tabular}

Sumber: Hasil Olah Data SPSS, 2017

Tabel 8. Analisis Regresi Linier Sederhana

\begin{tabular}{|c|c|c|c|c|}
\hline \multirow{2}{*}{ Model } & \multicolumn{2}{|c|}{$\begin{array}{l}\text { Unstand. } \\
\text { Coefficients }\end{array}$} & \multirow{2}{*}{$\begin{array}{c}\text { Stand. } \\
\text { Coef. } \\
\text { Beta }\end{array}$} & \multirow{2}{*}{$\mathbf{T}$} \\
\hline & B & $\begin{array}{c}\text { Std. } \\
\text { Error }\end{array}$ & & \\
\hline Constant & 71.827 & 4.010 & & 17.912 \\
\hline $\begin{array}{l}\text { Stres } \\
\text { Kerja }\end{array}$ & -.743 & .084 & -.642 & -8.891 \\
\hline
\end{tabular}

Selain itu melalui model persamaan hasil analisis regresi linier sederhana pada 
tabel 8 dapat diketahui persamaan pada penelitian ini yaitu $\mathrm{Y}=71,827+(-0,743) \mathrm{X}$. Dari persamaan tersebut dapat diketahui bahwa jika para karyawan tidak merasakan stres kerja $(X=0)$ maka akan menghasilkan kinerja karyawan sebesar 71,827. Sementara jika terjadi peningkatan stres kerja satu satuan maka akan menurunkan kinerja karyawan sebesar 0,743. Dengan kata lain apabila karyawan tidak merasakan stres kerja maka kinerja karyawan akan baik dan sebaliknya bila karyawan merasakan stres kerja maka kinerja karyawan pun akan buruk. Kemudian dapat dilihat bahwa nilai signifikasinya yaitu 0,000. Nilai ini berarti bahwa koefisien regresi signifikannya kurang dari 0,05 . Maka dari itu dapat diketahui bahwa $\mathrm{H} 0$ ditolak dan Ha diterima.

Tabel 9. Hasil Uji Koefisien Determinasi

\begin{tabular}{|c|c|c|c|}
\hline $\mathbf{R}$ & $\begin{array}{c}\mathbf{R} \\
\text { Square }\end{array}$ & $\begin{array}{c}\text { Adjusted } \\
\text { R Square }\end{array}$ & $\begin{array}{c}\text { Std. Error } \\
\text { of the Estimate }\end{array}$ \\
\hline $.642^{\mathrm{a}}$ & .412 & .406 & 4.450 \\
\hline
\end{tabular}

Sumber: Olah Data SPSS, 2017

Selanjutnya dari tabel 9 dapat dilihat bahwa koefisien determinasi variabel stres kerja dengan kinerja karyawan memiliki korelasi sebesar $64,2 \%$ yang berarti hubungan variabel stres kerja dan variabel kinerja karyawan ada pada tingkat yang kuat. Selain itu pada koefisien determinasi dapat diketahui bahwa stres kerja berkontribusi sebesar $41,2 \%$ terhadap kinerja karyawan. Sedangkan sisanya yaitu $58,8 \%$ dijelaskan oleh faktor-faktor lainnya, misalnya sarana pendukung seperti keselamatan dan kesehatan kerja, sarana produksi, teknologi, kesejahteraan pegawai (upah/gaji, jaminan sosial dan kompensasi lainnya) dan juga pra sarana seperti kebijaksanaan pemerintah dan hubungan industrial manajemen (Widodo, 2015)

Penelitian ini membuktikan bahwa stres kerja yang dialami oleh karyawan dapat membuat kinerja karyawan menjadi buruk sesuai dengan teori Susanto (2010) yang mengatakan bahwa stres yang berlebihan, berkepanjangan, tak terpecahkan, akan berpengaruh negatif pada kesehatan dan kinerja. Selain itu juga sesuai dengan teori Hamid (2014) mengatakan beban kerja yang tidak proporsional akan berdampak pada rasa stres, terutama yang telah melampaui tingkat moderat akan menimbulkan dampak negatif, yaitu ketidakpuasan kerja yang selanjutnya akan berdampak pada motivasi yang rendah. Motivasi yang rendah tersebut akan menghasilkan kinerja yang buruk. Sementara karyawan yang terbebas dari stres akan merasakan tingkat kepuasan yang tinggi, sehingga motivasi kerjanya meningkat dan kinerjanya pun juga ikut meningkat.

\section{KESIMPULAN DAN SARAN Kesimpulan}

Tingkat stres kerja yang dirasakan oleh karyawan bagian produksi di PT Catur Kartika Jaya berada pada kategori yang tinggi. Faktor yang paling berpengaruh pada tingginya stres kerja pada karyawan bagian produksi di PT Catur Kartika Jaya adalah ambiguitas peran serta kurangnya kesempatan bagi karyawan bagian produksi untuk mengembangkan karir yang memiliki nilai rata-rata sama yaitu 4,67. Pada dimensi ambiguitas peran faktor stres tertinggi adalah para karyawan selalu memiliki tugas yang menumpuk dan berlebih. Selain itu pada dimensi pengembangan karir, faktor stres tertinggi adalah tidak adanya potensi untuk mengembangkan diri. Sementara pada dimensi hubungan kerja faktor stres kerja tertinggi yaitu para karyawan sering bekerja lebih dari jam kerja (lembur). Tingkat kinerja karyawan bagian produksi PT Catur Kartika Jaya hanya berada pada kategori cukup. Berdasarkan kelima dimensi yang 
ada diketahui bahwa dimensi kinerja tertinggi karyawan terdapat pada kualitas pekerjaan, sementara dimensi kinerja terendah yaitu pada ketepatan waktu. Kemudian dari dimensi kuantitas pekerjaan diketahui bahwa kuantitas pekerjaan para karyawan bernilai buruk karena sering tidak berhasil mencapai target per hari, lalu dari dimensi kualitas pekerjaan diketahui bahwa nilai terendah yang didapatkan para karyawan yaitu karena para karyawan tidak melakukan pekerjaan sesuai pedoman operasional, selanjutnya dari dimensi ketepatan waktu diketahui bahwa ketepatan waktu para karyawan bernilai buruk, selanjutnya dari dimensi kehadiran diketahui bahwa nilai terendah didapatkan para karyawan karena tidak datang bekerja tepat waktu, kemudian terakhir dari dimensi kemampuan kerja sama didapatkan bahwa nilai terendah dari dimensi ini didapatkan karena para karyawan tidak bisa bekerja sama dengan rekan kerja secara baik.

Melalui analisis korelasi dan koefisien determinasi dapat diketahui bahwa antara stres kerja dan kinerja karyawan bagian produksi PT Catur Kartika Jaya memiliki hubungan negatif yang kuat dan signifikan dengan nilai korelasi -0,642. Selain itu stres kerja memiliki pengaruh sebesar $41,2 \%$ terhadap kinerja karyawan bagian produksi di PT Catur Kartika Jaya Bandung sehingga dapat diketahui bahwa kinerja karyawan yang hanya bernilai cukup pada PT Catur Kartika Jaya memang diakibatkan oleh stres kerja yang dialami para karyawan. Model persamaan hasil analisis regresi linear sederhana menunjukkan bahwa jika terjadi peningkatan stres kerja pada karyawan bagian produksi maka akan terjadi penurunan kinerja karyawan. Dengan kata lain apabila karyawan tidak merasakan stres kerja maka kinerja karyawan akan baik dan sebaliknya bila karyawan merasakan stres kerja maka kinerja karyawan pun akan buruk.

\section{Saran}

Setelah melakukan penelitian, pembahasan, dan penarikan kesimpulan, maka penulis mengusulkan saran yang dapat berguna bagi perusahaan, yaitu: Untuk ambiguitas peran sebaiknya PT. Catur Kartika Jaya memberikan job description yang jelas kepada setiap karyawan agar setiap karyawan memiliki tugas-tugas dan tanggung jawab yang jelas, sehingga karyawan bisa lebih fokus terhadap tugas-tugas utama yang telah diberikan. Perusahaan juga harus merekrut karyawan baru agar tidak terjadi kekurangan tenaga kerja yang bisa menghambat proses produksi serta agar para karyawan tidak memiliki peran ganda dalam pekerjaan. Lalu untuk pengembangan karir sebaiknya perusahaan mempertimbangkan untuk melakukan perombakan struktur organisasi agar lebih banyak jabatan yang tersedia karena berdasarkan struktur organsisasi yang ada struktur organisasi pada bagian produksi hanya sedikit sekali. Sebaikmya setiap bidang pada bagian produksi memiliki pengawas. Selain agar para karyawan bisa mengembangkan karirnya dengan adanya pengawas di tiap bidang produksi, pekerjaan para karyawan di tiap bidang pekerjaan dapat lebih terpantau.

Sementara untuk hubungan kerja sebaiknya perusahaan mengadakan acaraacara kebersamaan seperti piknik atau (gathering) untuk mempererat hubungan di antara para karyawan dan untuk menyegarkan pikiran. Selain itu penambahan karyawan juga dapat dilakukan untuk meningkatkan hubungan kerja karena dengan karyawan yang mencukupi, karyawan tidak perlu lagi sering bekerja lembur sehingga memiliki waktu untuk pergi bersama rekan-rekan kerja. Untuk kinerja karyawan guna meningkatkan kuantitas pekerjaan dan 
ketepatan waktu para karyawan, perusahaan sebaiknya melakukan penambahan karyawan agar karyawan tidak mengalami penumpukan tugas sehingga bisa mencapai target per hari serta tepat waktu dalam menyelesaikan tugas. Lalu untuk dimensi kualitas pekerjaan sebaiknya perusahaan lebih menekankan lagi agar karyawan melakukan pekerjaan sesuai pedoman operasional serta mengkaji ulang kebijakan tentang target penjualan sehingga karyawan dapat bekerja dengan tenang dan tidak terburu-buru. Selanjutnya untuk meningkatkan kehadiran para karyawan, sebaiknya perusahaan menegakkan kedisiplinan pada budaya organisasi perusahaan dan melakukan tindakan tegas pada karyawan yang sering terlambat. Terakhir untuk meningkatkan kemampuan kerja sama sebaiknya perusahaan meningkatkan fungsi pengawasan agar tidak terjadi konflik di antara para karyawan sehingga para karyawan bisa bekerja sama dengan baik.

\section{DAFTAR PUSTAKA}

Bangun, W. (2012). Manajemen Sumber Daya Manusia. Jakarta: Erlangga

Darodjat, T. A. (2015). Konsep-konsep Dasar Manajemen Personalia Masa Kini. Bandung: Refika Aditama

Hamid, S. (2014). Manajemen Sumber Daya Manusia Lanjutan. Yogyakarta: Deepublish

Hidayati, N., \& Trisnawati, D. (2016). Pengaruh Kepuasan Kerja Dan Stress Kerja Terhadap Turnover Intentions Karyawan Bag. Marketing PT. Wahana Sahabat Utama. EKSIS Vol XI No 1, 2016, ISSN:1907-7513. STIE PGRI Dewantara Jombang

Kompas.com. (2017). Wanita Lebih Rentan Stres Ketimbang Pria. lifestyle.kompas.com/read/2017/01 /01/ 130205023/wanita.lebih.rentan.stre s.ke timbang.pria

Kotteeswari, M., \& Sharief, T. (2014). Job Stress And Its Impact On Performance Employees Working In BPOS. International Journal of Advanced Research in Management,5 (2): pp: 19-27

Mauladi, F., \& Dihan, F. N. (2015). Pengaruh Stres Kerja Pada Kinerja Karyawan Dengan Kecerdasan Emosional Sebagai Variabel Moderasi (Studi pada Karyawan Rumah Sakit Condong Catur Yogyakarta). EFEKTIF Jurnal Bisnis dan Ekonomi Vol 6 No. 2 Desember 201551 -62

Olusegun, A. J., et al. (2014). An Overview Of The Effects Of Job Stress On Employees Performance In Nigeria Tertiary Hospitals. EKOHOMNHKA, ISSN 0350137X, EISSN 2334-9190, UDK 338 Vol. 60, October-december 2014, No. 4. Department of Management and Accounting, ObafemiAwolowo University, Ile Ife. Nigeria. www.ekonomika.org.rs/en/arhiva/P DF /arhiva.../4/13.pdf.

Rivai, V., \& Mulyadi, D. (2013). Kepeminimpinan dan Perilaku Organisasi, Ed. 2 Cet, 10. Jakarta: Rajawali Pers

Suara.com. (2017). Awas! Stres Bisa Perpendek Usia Harapan Hidup 5,5 Tahun.

m.suara.com/health/2016/11

/07/061948/awas-stres-bisa-

perpende k-usia-harapan-hidup-55tahun

Susanto, J. (2010). T'ai Chi-The Great Harmony. Seni Menjalani Kehidupan-Falsafah, Gerakan, Manfaat. Jakarta: PT Gramedia

Widodo, S. E. (2015). Manajemen Pengembangan Sumber Daya Manusia. Yogyakarta: Pustaka 
Pelajar

Zafar, Qadoos., et, al. (2015). The Influence

Of Job Stress on Employees

Performance in Pakistan. American

Journal of Social Science Research
Vol. 1, No. 4, 2015, pp. 221-225.

University Preston and University of The Punjab, Lahore, Pakistan. America: American Institute of Science 